\title{
A Case of Ochronosis with Atypical Manifestations Involving the Perioral Area and Sclera
}

\author{
Min Young Lee, Sook Jung Yun, Seung-Chul Lee, Young Ho Won, Jee-Bum Lee \\ Department of Dermatology, Chonnam National University Medical School, Gwangju, Korea
}

\section{Dear Editor:}

A 66-year-old woman presented with asymptomatic dark brownish ill-defined patches in the perioral area with discoloration noted a year prior to presentation (Fig. 1A). We received the patient's consent form about publishing all photographic materials. She had no other musculoskeletal, cardiac, or urinary symptoms, nor past or family history of similar symptoms. A skin biopsy from perioral area was obtained, revealing amorphous brownish materials in the

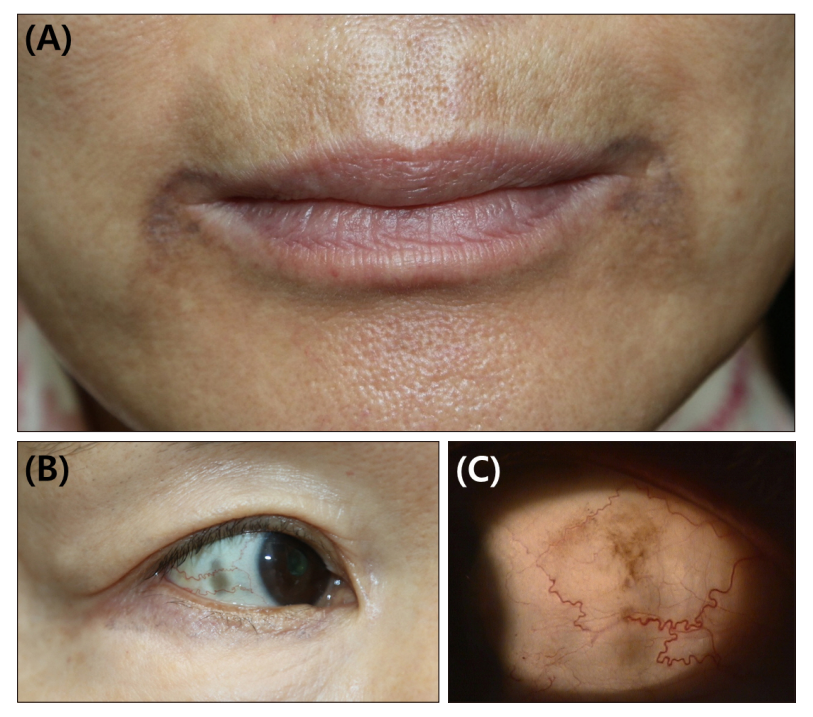

Fig. 1. Asymptomatic dark brownish ill-defined patches around the perioral area $(\mathrm{A})$, and hyperpigmentation of both sclerae (B: right eye, C: left eye). dermis. No remarkable epidermal pigmentations were found. Periodic acid-Schiff and ferric acid stains showed negative results (Fig. 2). We confirmed a diagnosis of ochronosis. Physical evaluation showed scleral hyperpigmentation bilaterally (Fig. 1B, C). Although she denied using any topical or oral medications, we found that she had been using an over-the-counter bleaching cream over 10 years. And she was also taking various health supplements. To exclude endogenous ochronosis, homogentisic acid quantification was done from random urine, and we were reported that it was in the normal range. She was treated using combination therapy comprising a carbon dioxide $\left(\mathrm{CO}_{2}\right)$ fractional laser and a Q-switched neomymium:yttrium-aluminum-garnet laser; however, she was lost to follow-up after 3rd treatment session because of no definite improvement.

Ochronosis is an uncommon disorder caused by accumulation of homogentisic acid in connective tissue ${ }^{1}$. There are two forms: endogenous and exogenous. Endogenous ochronosis or alkaptonuria, is a rare inherited metabolic disease. Absence of homogentisic acid oxidase leads to deposition of homogentisic acid. Alkaptonuria is presented as dark urine (when stands in air or in contact with alkali), arthropathy, discoloration over skin and cartilage (especially on the pinnae, cheeks, sclerae, axillae, inguinal area), heart valve damage, and kidney stones ${ }^{1,2}$.

Exogenous ochronosis is characterized by hyperpigmented macules on the face or neck ${ }^{1,3}$. It histopathologically resembles endogenous ochronosis, but without systemic symptoms and signs are found. Histopathological findings

\footnotetext{
Received December 13, 2017, Revised January 14, 2018, Accepted for publication February 5, 2018
}

Corresponding author: Jee-Bum Lee, Department of Dermatology, Chonnam National University Medical School, 42 Jebong-ro, Dong-gu, Gwangju 61469, Korea. Tel: 82-62-220-6684, Fax: 82-62-222-4058, E-mail: jbmlee@jnu.ac.kr ORCID: https://orcid.org/0000-0002-1477-4037

This is an Open Access article distributed under the terms of the Creative Commons Attribution Non-Commercial License (http://creativecommons.org/ licenses/by-nc/4.0) which permits unrestricted non-commercial use, distribution, and reproduction in any medium, provided the original work is properly cited.

Copyright (c) The Korean Dermatological Association and The Korean Society for Investigative Dermatology 

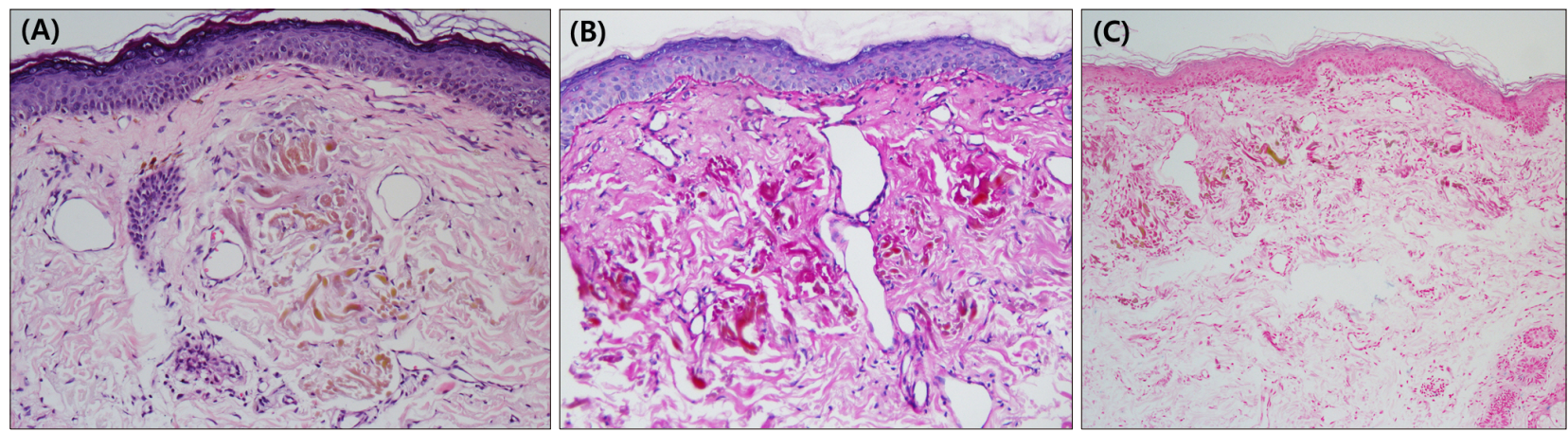

Fig. 2. (A) Histopathological examination shows amorphous brownish banana-shaped fibers in the dermis. No specific findings in the epidermis $(H \& E, \times 200)$. (B) Immunohistochemical staining reveals negative results with Periodic acid-Schiff $(\times 200)$, and $(C)$ ferric acid stain negative $(\times 40)$.

show ochre-colored banana-shaped fibers in the upper dermis. With progression of the disease, colloid milium or granulomas could be detected. Use of topical hydroquinone, phenol, resorcinol or oral antimalarials is known to cause exogenous ochronosis ${ }^{1,3}$. Retinoic acid, cryotherapy, $\mathrm{CO}_{2}$ laser, Q-switched ruby laser are used to treat this condition; however, most patients remain refractory to therapy ${ }^{1,3}$.

In our case, the exact causative agent remains unclear; however, the use of over-the-counter bleaching cream and health supplements that patient had been using over a long period time is highly suspicious. Mucocutaneous hyperpigmentation affecting both the skin and the sclera caused by oral minocycline has been reported previously ${ }^{4}$, however, this is the first report of exogenous ochronosis affecting both the skin and the sclera. In this case, zygomatic areas which are most commonly affected in exogenous ochronosis were clear, and pigmentations were only on the perioral area and the bilateral sclerae. We report a rare case of ochronosis showing atypical clinical manifestations.

\section{CONFLICT OF INTEREST}

The authors have nothing to disclose.

\section{ORCID}

Min Young Lee, https://orcid.org/0000-0001-9531-2565

Sook Jung Yun, https://orcid.org/0000-0003-4229-5831

Seung-Chul Lee, https://orcid.org/0000-0002-4428-3837

Young Ho Won, https://orcid.org/0000-0003-4640-4337

Jee-Bum Lee, https://orcid.org/0000-0002-1477-4037

\section{REFERENCES}

1. Kramer KE, Lopez A, Stefanato CM, Phillips TJ. Exogenous ochronosis. J Am Acad Dermatol 2000;42:869-871.

2. Khaled A, Kerkeni N, Hawilo A, Fazaa B, Kamoun MR. Endogenous ochronosis: case report and a systematic review of the literature. Int J Dermatol 2011;50:262-267.

3. Levin $\mathrm{CY}$, Maibach $\mathrm{H}$. Exogenous ochronosis. An update on clinical features, causative agents and treatment options. Am J Clin Dermatol 2001;2:213-217.

4. Skorin L Jr, Turpin S. Minocycline-induced hyperpigmentation of the skin, sclera, and palpebral conjunctiva. Can J Ophthalmol 2017;52:e79-e81. 